\title{
The effect of fines on the small-strain stiffness of sand-non plastic fines mixtures
}

\author{
Lu Zuo ${ }^{\text {i) }}$ and Béatrice A. Baudet ${ }^{\text {ii) }}$
}

\begin{abstract}
i) PhD student, Department of Civil Engineering, The University of Hong Kong, Pokfulam Road, Hong Kong
ii) PhD, Assistant professor, Department of Civil Engineering, The University of Hong Kong, Pokfulam Road, Hong Kong
\end{abstract}

\begin{abstract}
Sand-non plastic fines mixtures show a transitional mechanical behaviour as the fines content increases from a low level to a high level. The transition fines content, which is the boundary between sand-dominated and fines-dominated behaviour, can be found by simple laboratory tests e.g. maximum/minimum void ratio or stress path tests e.g. location of the normal compression line. The small-strain stiffness of sand-fines mixtures is supposed to have a similar transitional trend when the fines content is high enough to reach the transition fines content. A series of tests with local LVDTs was performed on samples of Leighton Buzzard sand mixed with non-plastic silt. The tests were performed during isotropic compression and shear tests in a triaxial apparatus. The fines content range was large enough to determine how the small-strain stiffness changes with the fines content. The value of transition fines content found from the triaxial tests are compared with those found from the bender element test results. Possible similarities and/or differences are discussed.
\end{abstract}

Keywords: sand, non-plastic fines, transitional fines content, small strain stiffness, laboratory test

\section{INTRODUCTION}

The mechanical behaviour of sand-non plastic fines mixtures has been studied from their static response (e.g., Lade et al., 1998; Thevanayagam and Mohan, 2000; Yang et al., 2006; Monkul and Ozden, 2007; Cabalar, 2011; Carrera et al., 2011) and dynamic response (e.g., Thevanayagam, 2000; Polito and Martin, 2001; Xenaki and Athanasopoulos, 2003; Papadopoulou and Tika, 2008; Dash et al., 2010). It has been proposed that the fines has a significant influence on the properties of a mixture when the fines content is reaching a value which is called transitional fines content $\left(\mathrm{FC}_{\mathrm{t}}\right)$. Lade et al. (1998) reported that the maximum void ratio $\left(\mathrm{e}_{\max }\right)$ and the minimum void ratio $\left(e_{\min }\right)$ of a mixture fall to the lowest value as the fines content increases to $\mathrm{FC}_{\mathrm{t}}$. The location of the normal compression line (NCL) is also affected by the non-plastic fines and shows an opposite trend before and after the $\mathrm{FC}_{\mathrm{t}}$ (e.g., Yang et al., 2006; Carrera et al., 2011). Thevanayagam (2002) proposed that when the fines content is lower than the transitional fines content, the behaviour of the mixture is governed by the sand matrix (sand-dominated) and an intergranular void ratio, $e_{s}$, which can be defined as:

$$
e_{s}=\frac{e+f_{c}}{1-f_{c}}
$$

where $e$ is the global void ratio of the mixture, $f_{c}$ is the fines content. When the fines content is higher than the transitional fines content, the behaviour of the mixture is governed by the fines matrix (fines-dominated) and an interfine void ratio, $e_{f}$, which can be defined as:

$$
e_{f}=\frac{e}{f_{c}}
$$

Soils show elastic stress-strain behaviour at small strain levels less than $10^{-4} \%$ to $10^{-3} \%$ strain level. The shear modulus at this level is the small-strain shear modulus, $G_{0}$. Under undrained triaxial loading condition, from the definition of shear modulus, $G_{0}$ can be calculated as:

$$
G_{0}=\frac{1}{3} \frac{\Delta q}{\Delta \varepsilon_{s}}=\frac{1}{3} \frac{\Delta \sigma_{a}}{\Delta \varepsilon_{a}}
$$

where $q$ is the deviator stress, $\varepsilon_{s}$ is the shear strain, $\sigma_{a}$ is the axial stress, and $\varepsilon_{a}$ is the axial strain. Bender elements are usually used to determine the value of $G_{0}$ based on the following equation:

$$
G_{0}=\rho V_{s}^{2}
$$

where $\rho$ is the mass density of the soil, and $V_{s}$ is the shear wave velocity. Researchers also studied on the empirical equations to determine the value of $G_{0}$ (e.g., 
Hardin and Richart, 1963; Iwasaki and Tatsuoka, 1977; Chung et al., 1984; Bellotti et al., 1996). Hardin and Richart (1963) proposed that $G_{0}$ is a function which can be expressed as:

$$
G_{0}=C_{g} f(e) p^{\prime^{n_{g}}} p_{a}^{1-n_{g}}
$$

where $f(e)$ is a function of global void ratio, $p^{\prime}$ is the mean effective stress, $p_{a}$ is a reference stress which equals to $100 \mathrm{kPa}$, and $C_{g}$ and $n_{g}$ are intrinsic soil parameters. Equation (5) can be rewritten as the following if a log-scale is used:

$$
\log G_{0}=n_{g} \log p^{\prime}+\log C_{g} f(e) p_{a}^{1-n_{g}}
$$

which shows a linear relation between $\log G_{0}$ and $\log p^{\prime}$, and the gradient is the value of $n_{\mathrm{g}}$. It suggests that, given sand-non plastic fines mixtures with the same fines content but different initial global void ratios, there should be a series of parallel lines on the $\log G_{0}$ $\log p^{\prime}$ plane.

The influence of fines on the small-strain stiffness has been studied by some researchers (e.g., Chien and Oh, 2002; Rahman et al., 2012). Salgado et al. (2000) experimented on Ottawa sand with up to $20 \%$ silt content, and proposed that $G_{0}$ decreases as the fines content increases. But how the fines affects the intrinsic soil parameter is still not clear especially when the fines content is higher than the transitional fines content $\mathrm{FC}_{\mathrm{t}}$.

\section{EXPERIMENTAL PROGRAM}

\subsection{Testing material}

Standard Leighton Buzzard Sand (LBS) was used as the host sand in this study. The particles are round to sub-round as shown in Fig. 1 (above), and the diameters range from 0.6 to $1.18 \mathrm{~mm}$ with a mean particle size $D_{50}=0.89 \mathrm{~mm}$. The specific gravity $G_{s}$ of LBS is 2.67 .

The non-plastic fines used in this study consist of crushed silica from mainland China which has angular particles as shown in Fig. 1 (below). The particle size ranges from 0.48 to $104.71 \mu \mathrm{m}$ with a mean particle size $D_{50}=13.7 \mu \mathrm{m}$. The specific gravity $G_{s}$ of the silt is 2.60 .

More information of the host sand and silt is given in Table. 1.

\subsection{Testing procedure}

A series of triaxial tests, some with local LVDTs, was performed to obtain the shear strength and small-strain stiffness of sand-non plastic fines mixtures with different fines contents.

The specimens were $38 \mathrm{~mm}$ in diameter by $76 \mathrm{~mm}$ in height (for the shear tests), and $50 \mathrm{~mm}$ in diameter by $100 \mathrm{~mm}$ in height (for the isotropic tests with LVDTs). Specimens of clean sand and sand-fines mixtures with $10 \%, 20 \%$, 30\%, 40\% fines content were tested. Here the fines content is the percentage of the dry mass of

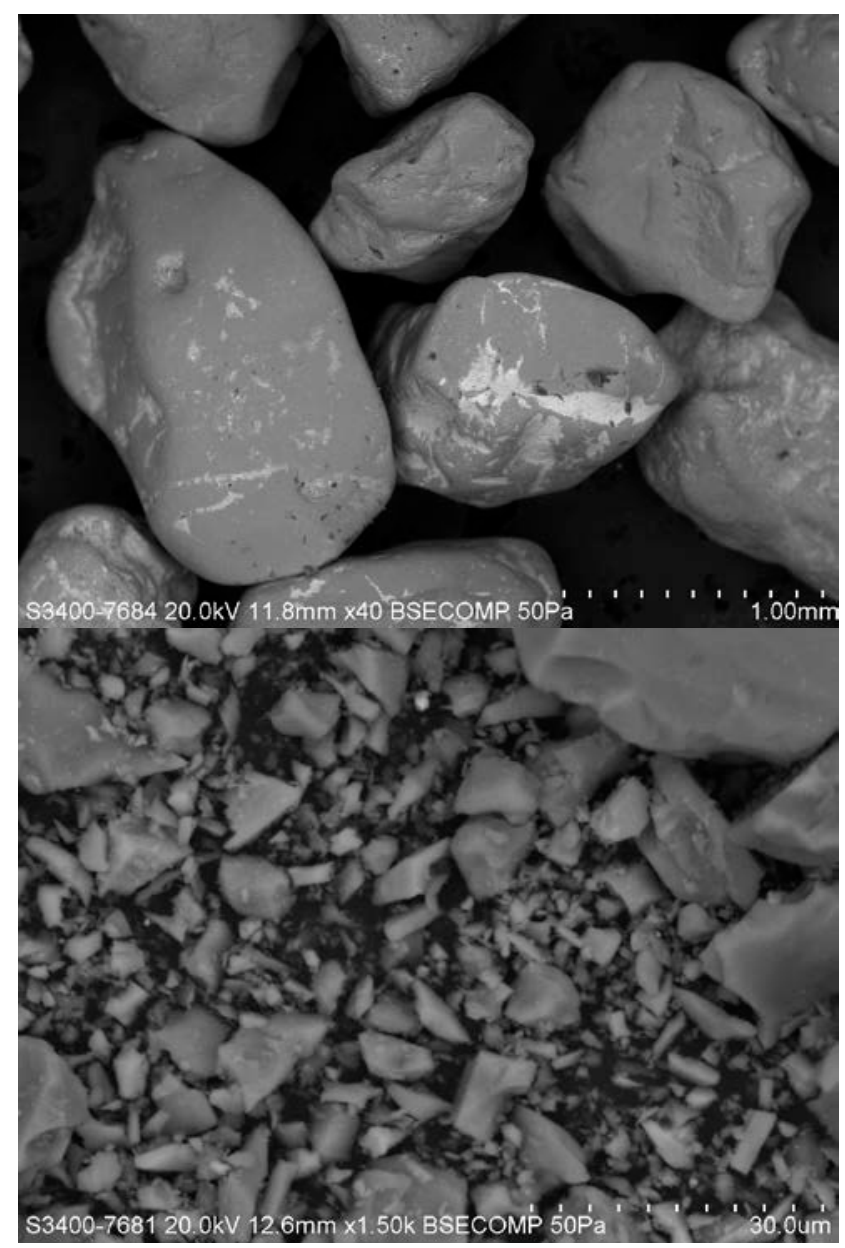

Fig. 1. Particles of LBS and crushed silica.

Table 1. Index properties of the host sand and silt.

\begin{tabular}{c|c|c}
\hline & Host sand & Silt \\
\hline Particle shape & round, sub-round & angular \\
\hline Maximum particle size $(\mathrm{mm})$ & 1.18 & 0.1047 \\
\hline Mean particle size $D_{50}(\mathrm{~mm})$ & 0.89 & 0.0137 \\
\hline Minimum particle size $(\mathrm{mm})$ & 0.6 & 0.00048 \\
\hline Coefficient of uniformity $C_{u}$ & 1.36 & 9.07 \\
\hline Specific gravity $G_{s}$ & 2.67 & 2.60 \\
\hline Maximum global void ratio $e_{\max }$ & 0.764 & - \\
\hline Minimum global void ratio $e_{\min }$ & 0.569 & - \\
\hline
\end{tabular}

silt over the total dry mass of the mixture. Moist tamping at water content of $5 \%$ was used to prepare the specimen and the specimen was divided into four or five layers during the preparation. Saturation was achieved by passing the $\mathrm{CO}_{2}$ through the specimen from bottom to top drainage pipe for about 30mins, then followed by de-aired water for another 30mins. The back pressure was used afterwards to obtain a B-value above 0.95, and the effective stress was kept at $10 \mathrm{kPa}$ at the same time. After the saturation, consolidation was conducted to different effective stresses from $100 \mathrm{kPa}$ to $600 \mathrm{kPa}$ for different specimens. Undrained triaxial tests were then performed on the smaller specimens with a loading speed of $0.38 \mathrm{~mm} / \mathrm{min}$. The tests were stopped at an axial strain of $30 \%$ where 
the deviatoric stress and pore water pressure mostly found to be constant and which was considered as the critical state. After the test, the mass of saturated and oven-dried specimen was measured to check with the initial void ratio before test. The evolution of the critical state line could then be examined for the different fines contents.

The larger specimens were subjected to isotropic compression. Local instrumentation was used with two axial local LVDTs directly fixed on the specimens. The specimen was $50 \mathrm{~mm}$ in diameter and $100 \mathrm{~mm}$ in height, the precision of the LVDT was $0.0001 \mathrm{~mm}$, with which an axial strain less than $10^{-4} \%$ to $10^{-3} \%$ could be measured. The specimens were consolidated to $600 \mathrm{kPa}$ in stages of $100 \mathrm{kPa}$. The small-strain stiffness was measured after the completion of each level consolidation by performing short undrained shearing tests within the elastic range at a loading speed of $0.006 \mathrm{~mm} / \mathrm{min}$. On reaching a local axial strain of $5 \times 10^{-4 \%}$ the specimen was then consolidated to the subsequent stage. The evolution of the small-strain stiffness with stress level could thus be examined for the different fines contents.

\section{TESTING RESULTS AND DISCUSSION}

\subsection{Shear strength and critical state}

Critical state was considered to be reached when the axial strain was at $30 \%$, at which the specimens generally reached a constant deviatoric stress and pore water pressure. Fig. 2 shows the typical stress-strain behaviour of a specimen prepared at $20 \%$ fines content with different initial void ratios. The deviatoric stress is normalized by the mean effective stress, and it is observed that the value of $\mathrm{q} / \mathrm{p}$ ' remains stable at large strain. The intergranular void ratio $e_{s}$ was kept constant for specimens of clean sand, and $10 \%$ and $20 \%$ fines content mixtures in some undrained triaxial tests; some typical results are shown in Fig. 3 where $e_{s}$ was kept at

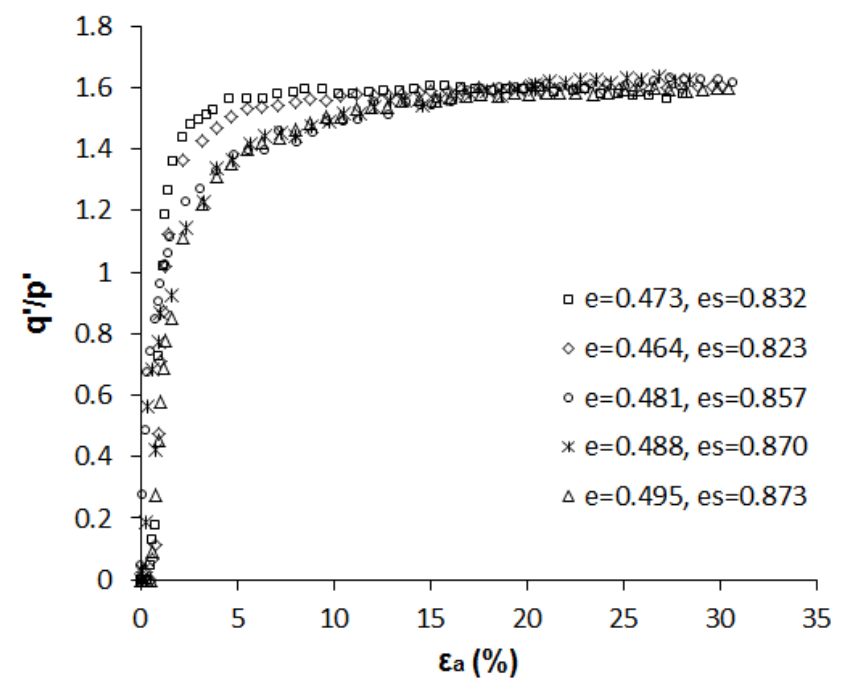

Fig. 2. Typical stress-strain behaviour of $20 \%$ fines content mixtures.
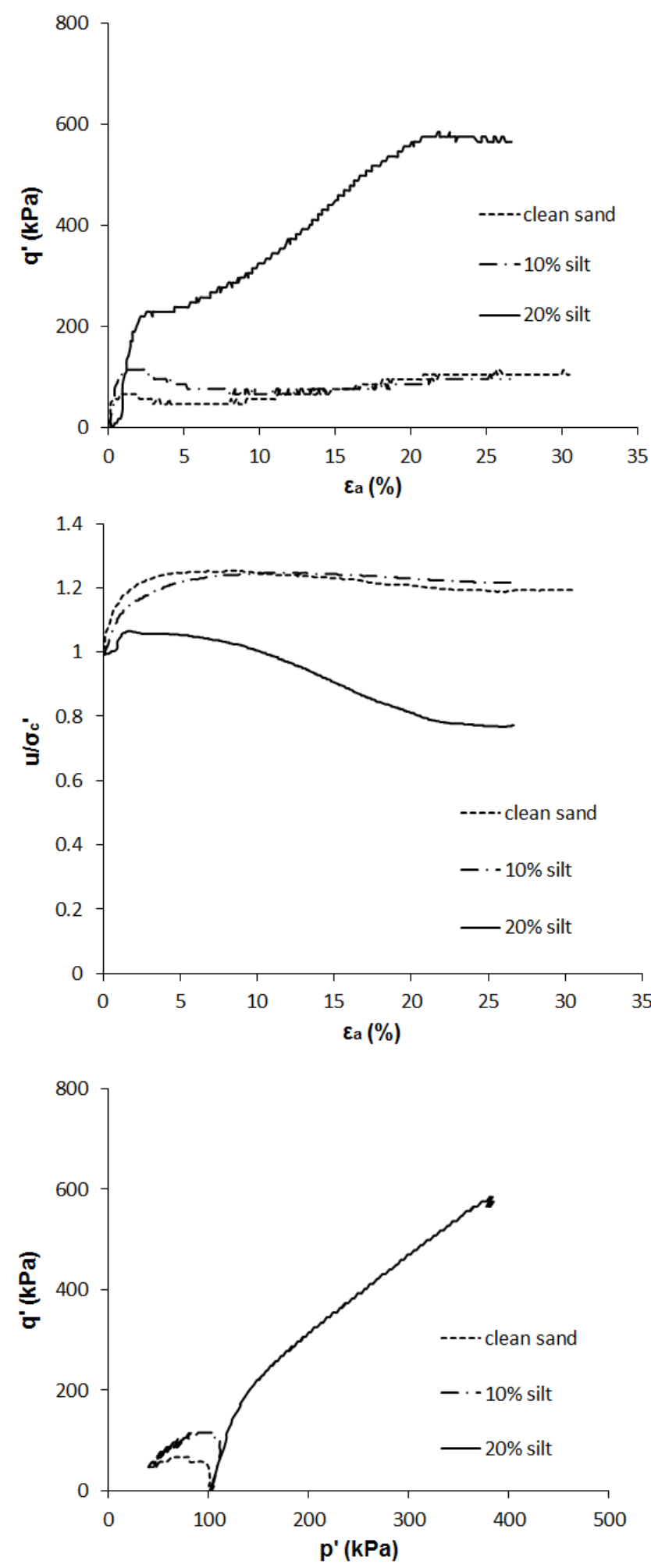

Fig. 3. Undrained triaxial test results for clean sand, $10 \%$ and $20 \%$ fines content mixtures at $e_{s}=0.825$.

0.825. Under the same initial confining pressure of $100 \mathrm{kPa}$, similar contractive behaviour is observed for the clean sand and the $10 \%$ silt content mixture despite a slight increase in peak shear stress of the $10 \%$ silt content mixture while the $20 \%$ silt content mixture shows a very different dilative behaviour with a much 
larger deviatoric stress. This shows that when the fines content is very low (e.g. less than $10 \%$ ), the fines do not have much contribution to the force chain in the soil even under large shear strain condition. But with the increase of fines content, the silt starts to enhance the contacts between particles until the fines content reaches the $\mathrm{FC}_{\mathrm{t}}$. This effect leads to a higher shear stress under large shear strain.

The critical state lines for clean sand and sand-fines mixtures with different fines contents are shown in Fig. 4. The critical state lines first move down with the value fines content increases to $30 \%$ and then start to move up, which indicates that the value of transitional fines content $\mathrm{FC}_{\mathrm{t}}$ is $30 \%$.

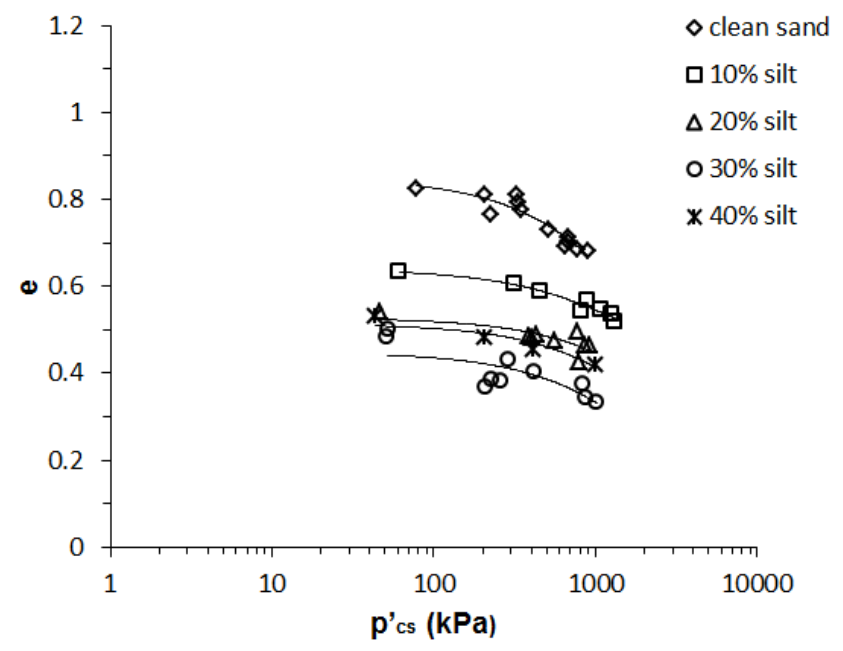

Fig. 4. Critical state lines of clean sand and sand-fines mixtures.

\subsection{Small-strain stiffness}

The intergranular void ratio $e_{s}$ was also kept at a constant value ( $e_{s}=0.748$ in this case) for the clean sand, $10 \%$ and $20 \%$ fines content mixtures during the isotropic compression, and the results are shown in Fig. 5. The small-strain stiffness, compiled from the data from the LVDTs, and the mean effective stress show a nearly linear relation in log-scale with a gradient $\mathrm{n}_{\mathrm{g}}$. Compared to clean sand, the sand-fines mixtures have lower small-strain stiffness $G_{0}$ under low confining stress, but then the value of $G_{0}$ of the mixtures increases more significantly as the confining stress increases. This indicates that under small strain condition, the effect of the fines is sensitive to the confining pressure. Under low confining pressure, part of the contacts between sand particles are separated by fines which leads to a lower $G_{0}$ value, but the contacts between sand particles increase with the increase of confining pressure, and at the same time part of the fines starts to enhance the contacts between particles which leads to a larger increasing speed of $G_{0}$ value. At the confining pressure of $600 \mathrm{kPa}$, the mixture with $10 \%$ fines content has almost the same $G_{0}$ value as the clean sand while the mixture with $20 \%$ fines content has a higher $G_{0}$ value than clean sand. It shows that when the fines content is low (e.g. less than 10\%), the fines do not contribute much to the force chain, but with the increase of fines content, the silt starts to participate in the force chain.

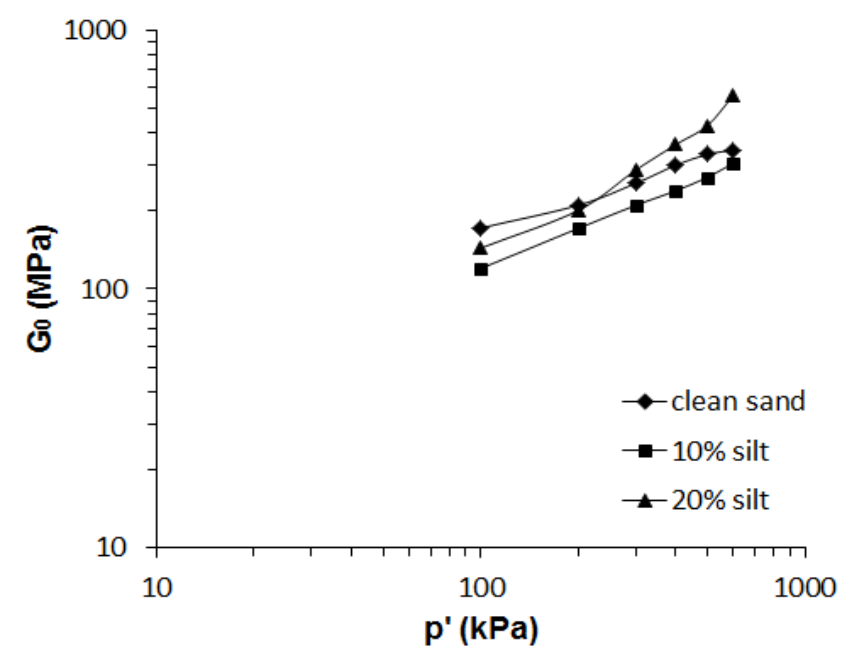

Fig. 5. Triaxial with local LVDTs test results of clean sand, 10\% and $20 \%$ fines content mixtures at $e_{s}=0.748$.

Regression analysis was used to determine the value of $n_{g}$ and the results are shown in Table. 2 and Fig. 6. The value of $n_{g}$ reaches a maximum at a fines content of $30 \%$ and then starts to decrease, which shows that the enhancement by fines is optimal when the fines content reaches $30 \%$. A transitional fines content of $30 \%$ can be obtained here, which is the same value as found from the critical state lines. This can be considered as another method for the determination of the value of $\mathrm{FC}_{\mathrm{t}}$.

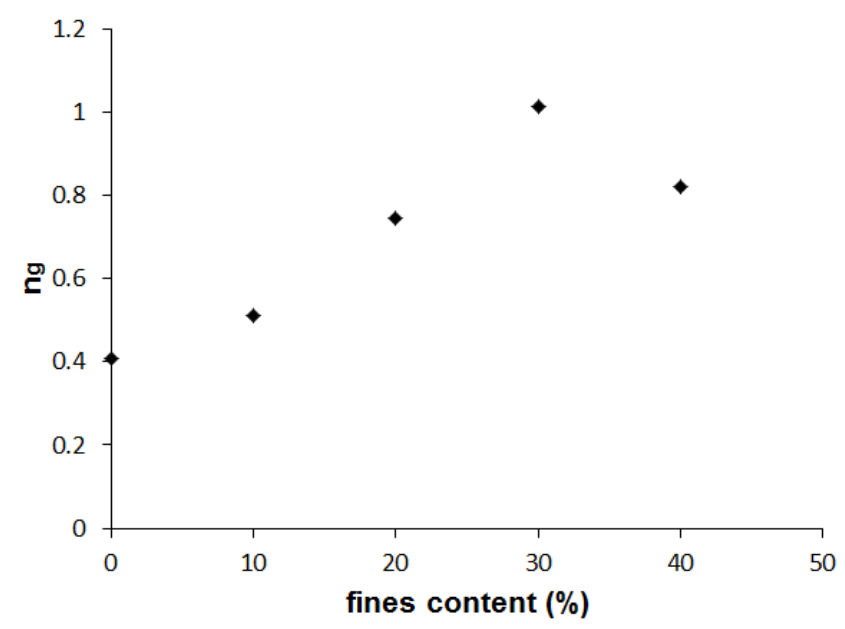

Fig. 6. Change of $n_{g}$ for the clean sand and sand-fines mixtures.

Table 2. Value of $n_{g}$ for the clean sand and sand-fines mixtures.

\begin{tabular}{c|c|c}
\hline Fines content (\%) & $n_{g}$ & $\mathrm{r}^{2}$ \\
\hline 0 & 0.4091 & 0.9859 \\
\hline 10 & 0.5121 & 0.9986 \\
\hline 20 & 0.7444 & 0.9755 \\
\hline 30 & 1.0127 & 0.9937 \\
\hline 40 & 0.8198 & 0.9972 \\
\hline
\end{tabular}




\section{CONCLUSIONS}

A series of triaxial tests was performed to obtain the shear strength and small-strain stiffness of sand-non plastic fines mixtures with different fines contents. It is found that the soil behaves more strongly with the increase of fines content from 0 to the value of $\mathrm{FC}_{\mathrm{t}}$ in both large strain and small strain conditions, although under small strain condition, the fines start to strengthen the soil under relatively large confining pressure.

The transitional fines content $\mathrm{FC}_{\mathrm{t}}$ is found to be $30 \%$ for the mixture of Leighton Buzzard Sand and crushed silica from both the critical state lines and intrinsic soil parameter $n_{g}$. Determination of $\mathrm{FC}_{\mathrm{t}}$ from the small-strain stiffness parameter is considered to be a reasonable method.

\section{REFERENCES}

1) Bellotti, R., Jamiolkowski, M., Lo Presti, D.C.F. and O’Neill, D.A. (1996): Anisotropy of small strain stiffness in Ticino sand, Géotechnique, 46(1), 115-131.

2) Cabalar, A.F. (2011): The effects of fines on the behavior of a sand mixture, Geotechnical and Geological Engineering, 29(1), 91-100.

3) Carrera, A., Coop, M. and Lancellotta, R. (2011): Influence of grading on the mechanical behaviour of Stava tailings, Géotechnique, 61(11), 935-946.

4) Chien, L.K. and Oh, Y.N. (2002): Influence of fines content and initial shear stress on dynamic properties of hydraulic reclaimed soil, Canadian Geotechnical Journal, 39(1), 242-253.

5) Chung, R.M., Yokel, F.Y. and Drnevich, V.P. (1984): Evaluation of Dynamic properties of sands by resonant column testing, Geotechnical Testing Journal, ASTM, 7(2), 60-69.

6) Dash, H.K., Sitharam, T.G. and Baudet, B.A. (2010): Influence of non-plastic fines on the response of a silty sand to cyclic loading, Soils and Foundations, 50(5), 695-704.

7) Hardin, B.O. and Richart, F.E.Jr. (1963): Elastic wave velocities in granular soils, J. Soil Mech. Found. Div., ASCE, 89(1), 33-65.

8) Iwasaki, T. and Tatsuoka, F. (1977): Effect of grain size and grading on dynamic shear moduli of sands, Soils and Foundations, 17(3), 19-35.

9) Lade, P.V., Liggio, Jr. C.D. and Yamamuro, J.A. (1998): Effects of nonplastic fines on minimum and maximum void ratios of sand, Geotechnical Testing Journal, ASTM, 21(4), 336-347.

10) Monkul, M.M. and Ozden, G. (2007): Compressional behavior of clayey sand and transition fines content, Engineering Geology, 89(3-4), 195-205.

11) Papadopoulou, A. and Tika, T. (2008): The effect of fines on critical state and liquefaction resistance characteristics of non-plastic silty sands, Soils and Foundations, 48(5), 713-725.

12) Polito, C.P. and Martin, J.R. (2001): Effects of nonplastic fines on the liquefaction resistance of sands, Journal of Geotechnical and Geoenvironmental Engineering, 127(5), 408-415.

13) Rahman, M.M., Cubrinovski, M., and Lo. S.R. (2012): Initial shear modulus of sandy soils and equivalent granular void ratio, Geomechanics and Geoengineering, 7(3), 219-226.

14) Salgado, R., Bandini, P. and Karim, A. (2000): Shear strength and stiffness of silty sand, Journal of Geotechnical and Geoenvironmental Engineering, 126(5), 451-462.

15) Thevanayagam, S. and Mohan, S. (2000): Intergranular state variables and stress-strain behavior of silty sands, Géotechnique, 50(1), 1-23.

16) Thevanayagam, S., Shenthan, T., Mohan, S. and Liang, J. (2002): Undrained fragility of clean sands, silty sands, and sandy silts, Journal of Geotechninal and Geoenviromental Engineering, 128(10), 849-859.

17) Xenaki, V.C. and Athanasopoulos, G.A. (2003): Liquefaction resistance of sand-silt mixtures: an experimental investigation of the effect of fines, Soil Dynamics and Earthquake Engineering, 23(3), 1-12.

18) Yang S., Lacasse, S. and Sandven, R. (2006): Determination of the transitional fines content of mixtures of sand and non-plastic fines, Geotechnical Testing Journal, ASTM, 29(2), 102-107. 